\title{
RECURSOS ESTILÍSTICOS EN LA PRODUCCIÓN NARRATIVA DE LAS NOVELAS BARTLEBY Y COMPAÑÍA Y EL MAL DE MONTANO DE ENRIQUE VILA-MATAS
}

\author{
ÓSCAR GUTIÉRREZ MUÑoZ
}

Universidad de Concepción, Chile

\begin{abstract}
Resumen: El presente trabajo busca hacer un análisis de los recursos estilísticos utilizados por el escritor español Enrique Vila-Matas en la construcción de sus novelas Bartleby y compañia y El mal de Montano. Nos centraremos en la utilización de ciertos aspectos de los mecanismos intertextuales dispuestos en la elaboración de la fabula que da lugar a ambas novelas. Reparamos sobre la construcción de los personajes y las relaciones que establecen dichas figuras con el archivo y la tradición literaria.
\end{abstract}

Palabras clave: intertextualidad, Enrique VilaMatas, Bartleby, Montano, hipertextualidad, paratextualidad

\begin{abstract}
In this paper we attempt to analyze the stylistic resources used by the Spanish writer Enrique Vila-Matas in the construction of his novels Bartleby \& Co., and El mal de Montano. We focus on the use of certain aspects of intertextual mechanisms, displayed in the development of the fable, which gave rise to these novels. Thus, we reflect on the construction of the characters, as well as on their relationship to both the archive and literary tradition.
\end{abstract}

Key words: intertextuality, Enrique Vila-Matas, Bartleby, Montano, hypertext, paratextuality

\section{Intertextualidad como poética}

Vila-Matas en su proyecto narrativo abarca un amplio espectro de formas de construcción literaria (novela, cuento, ensayo, crítica, periodismo, crónica, diario de viaje), además demuestra con solvencia una voluntad de estilo, pues en sus trabajos siempre se pueden apreciar marcas estilísticas de uso constante (pastiche, autoficción, mezcla de géneros literarios). El autor además siempre utiliza una herramienta fundamental, la cual se erige como mecanismo primordial del proyecto literario vilamateano, la intertextualidad. Este dispositivo de creación literaria, es utilizado en todas sus formas y modalidades para entregar sustancia y contenido a un proyecto intelectual de carácter mordaz y ácido, que a través de estas redes literarias y lingüísticas plantea cuestionamientos al sujeto contemporáneo y al paradigma sociocultural en el cual este individuo se desenvuelve. La intertextualidad será, por lo tanto, el elemento central en que nos detendremos en el presente artículo, el cual reflexiona sobre dos de 
Recursos estilísticos en la producción narrativa de las novelas
Bartleby y compaña y El mal de Montano de Enrique Vila-Matas

sus obras pertenecientes a la denominada trilogía de la desaparición, que se construye a través de ejercicios dialógicos entre uno y varios textos.

Bartleby y compañía (2001) es la recopilación y reinvención de la denominada literatura "bartleby", mientras que El mal de Montano (2002) es la formulación de un ejercicio literario como proyecto de vida. Ambas novelas plantean cuestionamientos, demuestran similitudes, prefiguran ciertos síndromes y "síntomas" del hombre contemporáneo, a la vez que se adscriben perfectamente a lo que podríamos llamar paradigma narrativo intertextual.

Para entrar a dicho análisis relacionaremos la forma en que el autor catalán construye a sus sujetos literarios con ciertas propuestas del discurso bajtiniano. El crítico ruso se ha encargado de señalar: "Es necesario tomar en consideración el peso psicológico que tienen en la vida las palabras de los otros sobre nosotros, y la importancia que tiene para nosotros el modo en que entendemos e interpretamos esas palabras de los otros." "Sentencia que aporta sentido en la distinción que hace el narrador español sobre los síndromes literarios (Bartleby y Montano), en la medida que la características de dichos síndromes, escritores del no y sujetos sometidos a sobredosis literaria, generan una forma particular de abordar la realidad a partir de las características estos males. Situación que el autor catalán se encarga de evidenciar, y por supuesto narrar. ${ }^{2}$

Este constante análisis sobre la contaminación literaria permite plantear las bases para analizar el carácter dialógico de la literatura. Bajtín subraya que el discurso literario bajo ninguna circunstancia sería un discurso cerrado o una construcción ostracista, pues las cualidades del lenguaje funcionarían a partir de un plurilingüismo efectivo, instancia que hace entrar en contacto diferentes voces, diferentes actores y diferentes discursividades en un mismo plano textual. De este modo y a partir de la interacción de distintos tipos de modalidades literarias se facilita la formación de un híbrido novelesco, el cual "tiene como objetivo iluminar un lenguaje con la ayuda de otro ya que no tiene sentido, estudiar la palabra desde su interior ignorando su orientación hacia afuera: el prosista utiliza las palabras ya pobladas de intenciones sociales ajenas y las obliga a servir a sus nuevas intenciones, a servir al segundo amo."3

La idea bajtiniana del híbrido novelesco, y de la utilidad y la intención de la literatura, como entidad autovalente y suprareal, sirven como premisas para entender el proyecto vilamateano, pues tanto El mal de Montano, como Bartleby y compañía comparten

\footnotetext{
${ }^{1}$ Mijail BAJTIN, Estética de la creación verbal (10ª edición), México, Siglo XXI, 1999, 76.

${ }^{2}$ La creación de estos tipos de sujetos literarios es un aspecto frecuentemente desarrollado en la obra de Vila-Matas, pues dicha característica no solamente se encuentra presente en los libros antes mencionados. Novelas como Historia abrevia de la literatura portátil (1985) o Kassel no invita a la lógica (2014), son entre otros trabajos archivos literarios, cartografías que recorren una determina historia y tradición literaria. Espacios que generan tipos particulares de personajes, y que el autor se encarga de identificar, caracterizar y ficcionalizar.
}

${ }^{3}$ BAJTIN, op. cit., 124. 
la hibridación en su concepción como libros. Además de estas sutilezas ambas novelas plantean la noción de archivo, de almacenar conceptos para la creación de registros de sujetos literarios.

Ambas novelas también presentan similitudes en temas estilísticos (en relación a la identidad vilamateana) y en nociones de género (novela-metaliteraria). Ambas cualidades son compartidas a tal punto que en la narración por momentos una novela pareciese estar escribiendo a la otra, como en el siguiente extracto de El mal de Montano: "finales del siglo XX el joven Montano, que acababa de publicar su peligrosa novela sobre el enigmático caso de los escritores que renuncian a escribir, quedó atrapado en las redes de su propia ficción y se convirtió en un escritor."'4

En Bartleby y compañia Vila-Matas utiliza el registro y la formulación de un archivo para dar lugar a la novela. "Hoy más que nunca porque empiezo — 8 de julio de 1999_ este diario que va a ser al mismo tiempo un cuaderno de notas a pie de página que comentarán un texto invisible y que espero que demuestren mi solvencia como rastreador de bartlebys." 5 Ambos trabajos, novelas de un aire marcadamente intertextual, tanto en su estructura como en los ejercicios que dan lugar a su creación, perfectamente pueden ser analizadas a partir de las características de dicho mecanismo de creación literaria.

El término intertextualidad se lo debemos a Julia Kristeva, quien considera que "Tout texte se construit comme une mosaïque de citations, tout texte est absortion et transformation d'un autre texte" 6 , dicha propuesta es similar a la postura vilamateana la cual se sostiene a través de las ideas de Benjamín : "Decía Walter Benjamin que en nuestro tiempo la única obra realmente dotada de sentido - de sentido crítico también- debería ser un collage de citas, fragmentos, ecos de otras obras. Yo a ese collage le añadí en su momento frases e ideas relativamente propias y poco a poco fui construyéndome un mundo autónomo, paradójicamente muy ligado a los ecos de otras obras." 7

Esta afirmación respecto a vivir rodeado de citas y construir la obra literaria a través de ecos de otras obras nos permite establecer diálogos con los postulados de Wolfgang Iser y cómo desde sus espacios de la teoría de la recepción, podemos comprender mejor esta noción de Arché o archivo que realiza el autor. Iser plantea la idea de "repertorio", esta noción sería el aporte personal del lector, que ya no tendría relación

\footnotetext{
${ }^{4}$ Enrique VILA-MATAS, El mal de Montano, Barcelona, Anagrama, 2002, 6.

${ }^{5}$ Enrique VILA-MATAS, Bartleby y compañia, Barcelona, Anagrama, 2001, 3.

6 Julia KRISTEVA, "Pour une sémiologie des paragrammes", in: Semeiotike: recherches pour une sémanalyse, Paris, Seuil, 1969, 121.

7 VILA-MATAS (2002), op. cit., 195.

${ }^{8}$ Wolfgan Iser define su noción de repertorio no solo en relación al archivo personal de lecturas y conocimientos culturales que posea el lector, y que estén relacionados con su formación y experiencia personal, la cuales indudablemente aportan en el desarrollo de la experiencia estética que es la lectura, sino que también lo relaciona con el contexto cultural en el que es desarrollada o
} 


\section{Recursos estilísticos en la producción narrativa de las novelas}

Bartleby y compañia y El mal de Montano de Enrique Vila-Matas

con la noción de lector histórico, sino más bien con las capacidades y conocimientos particulares del lector que entra en contacto con la dimensión estética del libro. La intertextualidad desde la perspectiva de Iser provocará una experiencia personal formando un juicio valorativo y estético, que solo tiene sentido desde las formulaciones teóricas de Kristeva y previamente de Bajtín. Por supuesto esta perspectiva de análisis no puede obviar el trabajo realizado por Iser a partir de las ideas de Roman Ingarden. Ambos críticos desmenuzaron las posibilidades del campo de la recepción literaria, en relación a la idea misma de repertorio, que por supuesto concentra el concepto intertextualidad, en relación al dinamismo de la obra de arte, especialmente a las perspectivas esquemáticas, las cuales facilitan o difuminan la intencionalidad primaria de un texto, a través de las referencias, los paratextos, metatextos y marcos culturales en los cuales son producidas. Entregando a partir de esta visualización los conceptos "espacio de vaguedad" (Unbestimmtheitsstelle) y "espacio vacío" (Leerstelle). González de Canales leyendo a Ingarden apunta: "En su artículo "Concretización y reconstrucción", Ingarden defendía que toda obra de arte literaria está conformada por necesarios espacios de vaguedad en los que el lector no tiene acceso a ciertas informaciones relativas a los ambientes y a los personajes que conforman el relato. Inspirado en los axiomas de Ingarden, en su libro El acto de leer, Iser postula lo que considera una constante provocación del texto autorial: la inclusión de la supresión como procedimiento creativo de asimetrías intra-textuales y estímulo de la imaginación del lector. Dicha privativa estrategia textual es utilizada por el escritor para generar la aparición de elipsis, los aquí llamados espacios vacíos, de los que se desprende la inexorable interrupción del flujo de lectura. En otras palabras, los espacios vacíos ${ }^{9}$ crean

es escrita una determinada obra. Es decir, las características, cualidades o normas sociales e históricas que influyen en el contexto de producción de una obra determinada. Elementos que no guardarían relación con la construcción e idealización de un "lector histórico", sino que más bien entregarían un campo de análisis y entendimiento al lector real que se ve enfrentado a dicha obra.

9 Específicamente la aparición de estos "espacios vacíos" (Leerstelle) en la narrativa vilamateana apunta al archivo personal del escritor, es decir fuerza al lector, quién al encontrarse frente a estos espacios liminares o ligeramente incompletos es invitado a activar la redes intertextuales presentes en el archivo personal del escritor catalán, para terminar de dar forma a la intención autoral. Como por ejemplo cuando el autor habla a través del personaje de su novela anterior sin mencionarla. "A finales del siglo XX el joven Montano, que acababa de publicar su peligrosa novela sobre el enigmático caso de los escritores que renuncian a escribir, quedó atrapado en las redes de su propia ficción y se convirtió en un escritor que, pese a su compulsiva tendencia a la escritura, quedó totalmente bloqueado, paralizado, ágrafo trágico". (VILA-MATAS, 2002, op. cit., 6.) En muchos puntos de la narrativa vilamateana dichos espacios invitan a conectar los distintos trabajos con otros con los cuales se encuentran emparentados, como por ejemplo el circuito intertextual de la trilogía de la desaparición, también llamada trilogía metaliteraria (Doctor Pasavento, El mal de Montano y Bartleby y compañia). 
estratégicos enclaves estructurales que sitúan al lector en el texto y lo obligan a completar con su imaginación los huecos que éste deja tras de sí." ${ }^{\prime \prime 10}$

A su vez, el fenómeno de repertorio sería entendido por Hans-Robert Jauss como horizonte de expectativas ${ }^{11}$, pues el autor señalaba: "La obra literaria no es un objeto existente para sí que ofrezca a cada observador el mismo aspecto en cualquier momento"12, sino que dicha construcción es elaborada a través de un proceso de recepción, análisis y valoración estética. De esta forma ambos autores -Jauss e Iserserían determinantes en la creación de este espectro de análisis literario conocido como posicionamiento hermenéutico, llevando a cabo ambos la fusión del repertorio estacionario generacional (lector histórico) y el del lector ideal (horizonte de expectativas), entendiendo que la asimilación escritural y lectora del proceso de intertextualidad es el hecho determinante para la formulación del grado de compresión y análisis del lector. "Asimismo, el binomio conceptual "expectativa" y "realización", propio de la teoría de la intencionalidad de Husserl, resulta clave en el desarrollo de la estética de la recepción. De acuerdo con Bech, "las realizaciones que identifica la fenomenología son siempre realizaciones de una expectativa [que] requiere la intención correspondiente."13

Intencionalidad que por supuesto esta implícitamente solicitada en las novelas del escritor catalán: "Uno podría abandonar la escritura ante las señales de lenta combustión de lo que es grande, ser su lector ideal, reflexivo, voraz, que ama las obras maestras, es superior al que intenta repetirlas o eclipsarlas, y convertirse así en el mejor lector del mundo."14

\footnotetext{
${ }^{10}$ Julia GONZALEZ DE CANALES CARCERENY, Placer e irritación del lector ante la obra literaria de Enrique Vila-Matas, Dissertation of the University of St. Gallen, School of Management, Economics, Law, Social Sciences and International Affairs to obtain the title of Doctor of Philosophy in Organizational Studies and Cultural Theory, Dissertation no. 4272 Difo-Druck Bamberg, 2014, 87.

${ }^{11}$ En torno a la construcción de las distintas obras de Vila-Matas el horizonte de expectativas pareciese estar claro. La intertextualidad trabajada por el autor pareciese tener un trazado definido. El cual se materializa a través de los vagabundeos que realizan los personajes que poblan sus obras. Desde los paratextos, hasta la orientación narrativa de las novelas, en los trabajos del catalán el lector tarde o temprano deberá someterse a la estructura lógica de la obra. Aquella dirección que lo lleva a la experiencia misma de la literatura, a reconocerse o dar cuenta de los males de las letras contemporáneas, aquellos a los que Vila-Matas se empeña en dar nombre y entregarles cuerpo, y qué usualmente emparentan una novela en particular con otros trabajos de su amplia producción literaria.

${ }^{12}$ H. Robert JAUSS, "La historia de la literatura como provocación de la ciencia literaria", in: La historia de la literatura como provocación, Barcelona, Península, 2000, 161.

${ }^{13}$ GONZALES DE CANALES, op. cit., 131.

${ }^{14}$ VILA-MATAS (2001), op. cit, 75.
} 
Recursos estilísticos en la producción narrativa de las novelas

Bartleby y compañia y El mal de Montano de Enrique Vila-Matas

Esta inclusión premeditada sobre la búsqueda e idealización del lector ideal, son acompañadas con diversos nombres, de importancias dispares; Derek Walcott, Joseph Conrad, Derain, Jaime Gil de Biedma se convierten, por lo tanto, en marcas textuales de un proyecto literario, en este caso del discurso del no. Y cuya inclusión además de señalar ciertas características particulares de un lector (conocimiento de autores, de poetas, idealización del mismo y desaparición del escritor), son también marcas de la generación de redes intertextuales a través de las cuales se desplaza la pluma del oriundo de Barcelona. Gerard Genette en Palimpsestos; la literatura en segundo grado (1982), define la intertextualidad ${ }^{15}$ como "relación de copresencia entre dos o más textos o presencia efectiva de un texto en otro"16, planteamiento a partir del cual elabora la distinción de cinco tipos básicos de transtextualidad ${ }^{17}$. Modalidades de creación literaria que en su totalidad encontramos presentes en las novelas que componen nuestro corpus de análisis. La primera modalidad, la cual también podríamos considerar como el mecanismo más básico de creación transtextual es la intertextualidad, la cual anteriormente ya definimos y que también consideraría la cita "forma más explícita y literal. Con comillas, con o sin referencia precisa", el plagio, "forma menos explícita y menos canónica. Es una copia no declarada pero literal"18, y la Alusión "enunciado cuya plena comprensión supone la percepción de su relación con otro."19 En Bartleby y compañía encontraremos estas diversas modalidades de relaciones textuales y semióticas. Respecto de la cita: "Ya puedo acabar, lo haré citando a Juan Benet: «Quien necesita fumar para escribir, o bien lo tiene que hacer a lo Bogart, con el humo enroscado al ojo (lo cual determina un estilo bronco), o bien ha de soportar que el cenicero se lleve la casi totalidad del cigarrillo.»" 20 , y la alusión: "Hemos aprendido a respetar a los embaucadores. En su nota para un prefacio no escrito para Las flores del mal, Baudelaire aconsejaba al artista que no revelara sus secretos más íntimos, y así revelaba el suyo propio: «نAcaso mostramos a un público a veces aturdido, otras indiferente, el funcionamiento de nuestros artificios? ¿Explicamos todas esas revisiones y variaciones improvisadas, hasta el modo en que nuestros impulsos más sinceros se mezclan con trucos y con el charlatanismo indispensable para la amalgama de la obra?»" 21

\footnotetext{
${ }^{15} \mathrm{El}$ término que prefiere utilizar es el de transtextualidad, sin embargo el paso de los años, y la utilización de la crítica se han decantado por el uso del término intertextualidad acuñado por Kristeva, siendo más universal que el término transtextualidad de Genette, sin embargo, esta diferenciación de nomenclatura no es otra cosa que una pugna teórica, pues en estricto rigor ambos catedráticos se refieren y describen el mismo fenómeno.

${ }^{16}$ Gérard GENETTE, Palimpsestos. La literatura en segundo grado, Madrid, Altea, 1989, 11.

17 Las cinco modalidades descritas son: intertextualidad, paratextualidad, metatextualidad, hipertextualidad y architextualidad

18 Idem.

${ }^{19}$ Idem.

${ }^{20}$ VILA-MATAS (2001), op. cit., 34.

${ }^{21}$ Ibidem, 29.
} 
A su vez en El mal de Montano encontramos igualmente estas modalidades; la cita "Diario de un genio. Me sabía de memoria alguno de sus párrafos y solía recitarlos en reuniones con los amigos, me acordaba de párrafos como éste: «¿Cómo voy a dudar de que todo lo que me acontece es enormemente excepcional?»"22, y la alusión, "André Bretón, que escribió en Nadja que Nantes era tal vez, con París, «la única ciudad de Francia donde tengo la impresión de que algo que vale la pena puede sucederme." 23 Además, la forma en la que son construidas ambas obras les permite adquirir el carácter lúdico de la textualidad, aquella cualidad que Derrida habría sindicado como la presencia o ausencia de textos en otros, a través de un juego de interacción dialógica: "El texto sería un juego libre de diferencias, un tejido o red de significaciones que remite a otros textos de forma ininterrumpida e infinita; la textualidad derrideana es un tejido de textos y lecturas, un proceso de significación dominado por el juego interminable de diferenciar y posponer, de la différance y la huella." 24

\section{Configuración hipertextual de Bartleby y compañía y El mal de Montano}

El segundo tipo de modalidades transtextuales propuestas por Genette es la paratextualidad, la relación que un texto mantiene con los paratextos de su entorno inmediato, "título, subtítulo, intertítulos, prefacios, epílogos, advertencias, prólogos, etc.; notas al margen, a pie de página, finales; epígrafes; ilustraciones; fajas, sobrecubierta, y muchos otros tipos de señales accesorias, autógrafas o alógrafas, que procuran un entorno (variable) al texto y a veces un comentario oficial u oficioso." 25 Las dos novelas que analizamos parten su creación ficcional a partir de la modalidad más usual de paratexto, es decir, desde el título mismo. Bartleby y compañia nos circunscribe al mundo de los bartlebys, sujetos y escritores que se adscriben a la negación del mundo, partiendo por la negación misma del individuo, proceso que inclaudicablemente desembocaría en la desaparición. El síndrome toma su nombre del cuento Bartleby el escribiente de Herman Melville, autor que es una de las piedras angulares del citacionismo vilamateano. Los bartlebys "toman su nombre del escribiente Bartleby, ese oficinista de un relato de Herman Melville que jamás ha sido visto leyendo, ni siquiera un periódico; que, durante prolongados lapsos, se queda de pie mirando hacia fuera por la pálida ventana que hay tras un biombo, en dirección a un muro de ladrillo de Wall Street; que nunca bebe cerveza, ni té, ni café como los demás; que jamás ha ido a ninguna parte, pues vive en la oficina, incluso pasa en ella los domingos; que nunca ha dicho quién es, ni de dónde viene, ni si tiene parientes en este mundo." 26

22 VILA-MATAS (2002), op. cit., 170.

${ }^{23}$ Ibidem, 25.

${ }^{24}$ J. E. MARTÍNEZ FERNÁNDEZ, La intertextualidad literaria, Madrid, Cátedra, 2001, 10.

${ }^{25}$ GENETTE (1989), op. cit., 11.

${ }^{26}$ VILA-MATAS (2001), op. cit., 3. 


\section{Recursos estilísticos en la producción narrativa de las novelas}

Bartleby y compañia y El mal de Montano de Enrique Vila-Matas

En este cuento, que presenta un marcado aire kafkeano, Melville somete al director de una oficina de copistas a ser acosado por la presencia de un empleado que no presenta emociones, no posee una historia que describa o explique su comportamiento y por supuesto no presenta ninguna aspiración ni tampoco desea ir a ninguna parte, un nihilista que se conforma con trabajar y responder a las interacciones sociales con la cortés frase, "preferiría no hacerlo". Este personaje literario, pasaría a ser el eje central del proyecto que Vila-Matas propone en Bartleby y compañia, sería el primer caso diagnosticado para explicar un síndrome literario. De esta forma y a partir de esta primera referencia paratextual se nos expone este síndrome literario que apunta a la negación del individuo llevada a límites tan profundos y abstractos como la desaparición. Una forma de literatura que está íntimamente ligada al desconcierto y la incapacidad de ciertos individuos de relacionarse de forma saludable con su entorno, pues en cierta medida los procesos deconstructivos de la sociedad imposibilitan la formación de una relación estable de los sujetos con dicho entorno. Paralelamente, El mal de Montano configura un paratexto de manera distinta al evidente juego paratextual de Bartleby y compañia, el montano no es un concepto o una idea inmediatamente literaria. El concepto montano es más bien la referencia inmediata al término biogeográfico referido a áreas de montaña localizadas por debajo de la línea arbolada o a Montano, heresiarca inspirador de la doctrina conocida como Montanismo. Por lo tanto, el paratexto en este nivel trabaja de forma diferente; en primer lugar funciona en un nivel semántico, pues los semas que construyen el título dan a conocer de forma prefigurativa el carácter del libro, la noción de síndrome. A su vez, la contratapa funcionando con la característica paratextual entrega información específica respecto de su carácter y el diálogo que entabla con la novela precedente; "Ésta es la crónica de un hombre de acción asfixiado de literatura y una contrarréplica de la parálisis literaria comentada por Enrique Vila-Matas en Bartleby y compañia. Considerada como una de sus novelas fundamentales." 27 A su vez la novela retoma la consideración de la desaparición de la literatura utilizando como epígrafe la siguiente cita; “Cómo haremos para desaparecer?. Maurice Blanchot". En este caso el epígrafe funciona en un nivel de paratextualidad, pues "plantea un diálogo entre dos textos, uno que se desarrolla íntegramente a la vista del lector y otro que se presenta como fragmento desgajado de una totalidad ausente, pero de algún modo representada"28 Este rasgo de paratextualidad permite al epígrafe adquirir nuevos niveles de literalidad, pues "la brevedad, el fragmentarismo, el carácter alusivo son rasgos que contribuyen a que el epígrafe se cargue de significación por diversas vías y se convierta, así, en elemento consustancial al texto que acompaña." 29

\footnotetext{
27 VILA-MATAS (2002), op. cit., contratapa

${ }^{28}$ Juan MONTERO, "Un modo de diálogo intertextual: El epígrafe literario de en Cántico, de Jorge Guillén”, in: Epos, XIII, UNED, Madrid, 1997, 190.

${ }^{29}$ Idem.
} 
Otro nivel de modalidades transtextuales que se despliegan en ambas novelas es la metatextualidad, que sería lo que une a un texto con el texto que lo comenta y analiza. Este fenómeno es bastante particular en el trabajo vilamateano por diversas razones. En primer lugar tenemos el fenómeno autoficcional. Esta cualidad del texto permite una reflexión metatextual del libro mismo, pues "las autoficciones tienen como fundamento la identidad visible o reconocible del autor, narrador y personaje del relato." 30 Situación a través de la cual el personaje constantemente reflexionará sobre el trabajo que realiza en sus dos viajes y registros literarios. El otro factor es la reflexión sobre la fábula, que hace el mismo personaje y voz narrativa de las novelas. "Me dispongo, pues, a pasear por el laberinto del No, por los senderos de la más perturbadora y atractiva tendencia de las literaturas contemporáneas: una tendencia en la que se encuentra el único camino que queda abierto a la auténtica creación literaria; una tendencia que se pregunta qué es la escritura y dónde está y que merodea alrededor de la imposibilidad de la misma y que dice la verdad sobre el estado de pronóstico grave — pero sumamente estimulante- de la literatura de este fin de milenio." 31

O este otro ejemplo en El mal de Montano: "Así fueron las cosas ayer por la noche en este cuarto de hotel donde ahora yo escribo este diario que se me está volviendo novela." 32 A su vez, ambos textos han sido sindicados como metaliteratura por la forma del relato (un relato fraccionado con diferentes constituyentes), y por su cariz ideológico, en relación al análisis y el mundo literario. "Vila-Matas nos cuenta algo más que el final de los grandes relatos, o el origen de una nueva condición de la literatura, nos habla de una invención que permite seguir escribiendo. Si convenimos que el significado de la deconstrucción es mostrar que las cosas, textos, instituciones, tradiciones, sociedades, no tienen significados definibles, que no tienen una misión determinada o determinable y que siempre exceden las fronteras que ocupan, la lectura de un texto, sea retórico o político, siempre está por llegar." 33

Otra modalidad de transtextualidad es la denominada architextualidad. El teórico francés define esta subdimensión de la transtextualidad como un rasgo taxonómico del paratexto, es decir, las dimensiones y las relaciones que se desprenden de las definiciones, cualidades y características del género artístico a los cuales pertenece, predisponiendo a que los lectores esperen ciertos patrones, o modalidades discursivas acordes al tipo de texto (novela, obra de teatro, poema) que van a leer. Es decir este tipo de intertextualidad propicia lo que podríamos denominar percepción genérica (de género literario): "La percepción genérica, como se sabe, orienta y determina en gran

\footnotetext{
${ }^{30}$ Manuel ALBERCA, El pacto ambiguo. De la novela autobiográfica a la autoficción, Madrid, Biblioteca Nueva, 2007, 31.

31 VILA-MATAS (2001), op. cit., 3.

32 VILA-MATAS (2002), op. cit., 36.

33 Antonio AGUILAR, "Literatura y deconstrucción: Lectura de Enrique Vila-Matas. Los escombros de la teoría", in: Revista de Observaciones Filosóficas, Facultad de Filosofía, UNED, Madrid, 2009, 3. http://www.observacionesfilosoficas.net/litydecons.html
} 


\section{Recursos estilísticos en la producción narrativa de las novelas}

Bartleby y compañia y El mal de Montano de Enrique Vila-Matas

medida el "horizonte de expectativas" del lector, y por lo tanto la recepción de la obra." 34 Además de esta modalidad de percepción genérica Genette también plantea una modalidad de redes comunicantes que da lugar a una forma de intertextualidad más compleja, la cual es una modalidad funcional que sirve para explicar la configuración del ejercicio literario de cartografía que el catalán realiza a través de sus obras. Esta modalidad es la hipertextualidad. "Se trata de lo que yo rebautizo de ahora en adelante hipertextualidad. Entiendo por ello toda relación que une un texto B (que llamaré hipertexto) a un texto anterior A (al que llamaré hipotexto) en el que se injerta de una manera que no es la del comentario [....]. Para decirlo de otro modo, tomemos una noción general de texto en segundo grado [renuncio a buscar, para un uso tan transitorio, un prefijo que subsuma a la vez el hiper -y el meta-] o texto derivado de otro texto preexistente. Esta derivación puede ser del orden, descriptivo o intelectual, en el que un metatexto [digamos tal página de la Poética de Aristóteles] «habla» de un texto Edipo Rey." $35 \mathrm{El}$ autor expone la relación que se desprende de dos textos y mediante la cual podemos entender las relaciones que Rosario Girondo y el rastreador de bartlebys realizan con sus espacios de significación textual y sus campos literarios y la funcionalidad de los mismos en relación a ellos. Genette ejemplifica este fenómeno con el hipertexto homérico la Odisea, y sus múltiples redes textuales. "La Eneida y el Ulysses son, en grados distintos, dos (entre otros) hipertextos de un mismo hipotexto: La Odisea. Como puede comprobarse a través de estos ejemplos, el hipertexto es considerado, más generalmente que el metatexto, como una obra propiamente literaria." 36 En el caso específico de Vila-Matas ambas novelas más que hacer un enlace particular con un hipertexto o metatexto, hacen referencia a una construcción hipertextual que es la denominada "Galaxia Gutemberg" 37 y que a grosso modo podríamos describir como el paradigma literario que el autor desarrolla en base a un exhaustivo y complicado trabajo intertextual, y que propone como poética personal, a partir de la cual produce las exégesis de su pensamiento literario. El trabajo vilamateano plantea una teoría de la ficción a partir de la cual construye una visión literaria que funciona como continuación de su proyecto literario, es por esto que utiliza la autoficción, pues a través de ese mecanismo construye su planteamiento intertextual.

Analicemos por lo tanto de qué forma se estructura en las novelas esta formulación y relaciones del hipertexto y el hipotexto. Vila-Matas plantea una poética lo suficientemente consciente como para estructurarla sin un planteamiento teórico mayor, su trabajo literario manifiesta sus convicciones estéticas las que ficcionalizadas

\footnotetext{
34 GENETTE (1989), op. cit., 14.

35 Idem.

${ }^{36}$ Idem.

${ }^{37}$ Este término lo hemos analizado en un trabajo anterior y en relación con Dublinesca (2010), novela posterior al proyecto "tríptico de la desaparición". Recomendamos nuestro artículo "Aproximaciones al archivo en Dublinesca de Enrique Vila-Matas", in: Logos: Revista de Lingüistica, Filosofia y Literatura, 24, n. 1, 2014, 30-39.
} 
(forman parte de la fábula de la novela) irrumpen en sus texto, en sus personajes. "Porque, vamos a ver, pensó Riba, si uno tiene la teoría, ¿para qué quiere hacer la novela? Y en el momento mismo de preguntárselo y seguramente para no tener una sensación tan grande de haber perdido el tiempo, incluso de perderlo al preguntárselo, comprendió que haberse pasado tantas horas en el hotel escribiendo su teoría general le había en el fondo permitido desembarazarse de ella. ¿Acaso un hecho así era desdeñable? No, desde luego. Su teoría seguiría siendo lo que era, lúcida y osada, pero iba a destruirla tirándola a la papelera de su cuarto." 38 Por supuesto el autor desestima lanzar su teoría a la papelera de su cuarto, prefiere utilizarla en los diferentes quiebres temáticos de su trabajo, en el ejercicio narrativo que de algún modo se ha ido instalando como una marca registrada del catalán, quien define su práctica narrativa como literatura construida a través de literatura.

Con la llamada trilogía de la desaparición, nuestro autor realiza tres escalas en este mise en abyme. En la primera analiza el fenómeno de la desaparición como un cartógrafo, es decir, Bartleby y compañia, la cual en su construcción de fichas se genera un registro, donde se visualizan las problemáticas y las principales características de la denominada literatura bartleby. En la segunda escala, El mal de Montano, se trabaja sobre una impostura donde el diario personal permite hacer desaparecer la identidad del escritor, y formular la identidad de un nuevo escritor a través del libro. Finalmente, en el tercer estadio, que se describe en Doctor Pasavento, la suplantación cumple el rol de la desaparición, el personaje central comienza a devenir distintas identidades como, por ejemplo, Doctor Pasavento o Doctor Ingravallo, jugando en esa tesitura que planteará Marc Augé, la sobremodernidad es "productora de no lugares, es decir, de espacios que no son en sí lugares, es decir de espacios que no son en sí lugares antropológicos y que, contrariamente a la modernidad baudeleriana, no integran los lugares antiguos." 39 Por lo tanto, la capacidad de adquirir nuevas identidades es la posibilidad del desplazamiento en esos no lugares dándole nuevas facultades a la desaparición del individuo.

Estas novelas que trabajan la desaparición en las modalidades descritas más arriba están estructuradas a partir de los mecanismos transtextuales propuestos por Genette. Detengámonos en Bartleby y compañia, en este caso particular el hipotexto será Bartleby, el escribiente de Melville, y el hipertexto que hace referencia a él la novela de VilaMatas. El contexto por supuesto será relacionar aquellos escritores cuya historia apunte a la desaparición, a dejar de escribir, o al nihilismo entendido como posibilidad de lucha (la funcionalidad del lenguaje y su mensaje) o como posibilidad de salida (desaparecer para volverse una realidad). De esta forma se suma al título la palabra compañía, dejando en claro que seguiremos a diferentes víctimas o exponentes de esta temática. El hipotexto por lo tanto sentará las bases en torno al cual el autor construye la novela, desarrollando y configurando el espacio de la oficina a partir del cual comienza a

${ }^{38}$ Enrique VILA-MATAS, Dublinesca, Barcelona, Anagrama, 2010, 164.

39 Marc AUGE, Los no lugares: Espacios de anonimato. Una antropología de la sobremodernidad, Barcelona, Gedisa 2008, 83. 


\section{Recursos estilísticos en la producción narrativa de las novelas Bartleby y compañia y El mal de Montano de Enrique Vila-Matas}

construir su archivo de Bartlebys, su colección de enajenados. Por lo tanto quizás la relación no será precisamente de estructuración textual o de referencia literaria específica, sino que más bien de colocación y articulación de la problemática de fondo, y la creación y visualización del espacio donde esta temática se desarrollaría, en este caso en particular una oficina, donde recalcamos el carácter de escribiente que asume el narrador catalán, grados de autoficción que lo emparentan al escribiente y copista, en cuanto trabajador que vive del salario de reproducir documentos y archivos.

En El mal de Montano la relación hipertextual sufre un desplazamiento, el cual daría sentido a la fábula de la novela. Usualmente el hipertexto se estructura o se escribe a partir de las influencias del hipotexto. Vila-Matas haciendo uso de su elegancia intertextual despliega los lazos de la novela con una película, La notte de Michelangelo Antonioni ${ }^{40}$. La película es un drama psicológico que ahonda en la incapacidad comunicativa. El conflicto se centra en la desgastada relación matrimonial entre un escritor en ascenso Giovanni Pontano (Marcello Mastroianni) y su esposa Lidia (Jeanne Moreau). Ambos personajes interactúan y se mueven en diversas situaciones y conflictos: la visita a un amigo moribundo en el hospital, el lanzamiento del prometedor libro del autor, la estancia en un restaurante, la invitación a la fitzgeraldiana fiesta de un industrial; y la relación que surge entre la hija de éste, Valentina (Monica Vitti) y el escritor Pontano. En este personaje en tanto encontramos la referencia transtextual al Montano, el Montano hace referencia al Pontano, a Giovanni Pontano el escritor. Esta similitud entre dos nombres bien podríamos considerarlas una casualidad, sin embargo, como todas las referencias vilamateanas ésta responde a un entramado intertextual complejo pero posible de reconstruir. En el Barcelona Review encontramos la siguiente columna del autor catalán: "Muchas veces me he visto obligado a contestar a la pregunta de por qué escribo. Al principio, cuando era muy joven y tímido, utilizaba la breve respuesta que daba André Gide a esa pregunta y contestaba: «Escribo para que me lean.» Si bien es cierto que escribo para que me lean, con el tiempo he aprendido a completar con otras verdades mi sincera respuesta a la pregunta de por qué escribo. Ahora, cuando me hacen la inefable pregunta, explico que me hice escritor porque 1) quería ser libre, no deseaba ir a una oficina cada mañana, 2) porque vi a Mastroianni en La noche de Antonioni; en esa película -que se estrenó en Barcelona cuando tenía yo dieciséis años- Mastroianni era escritor y tenía una mujer (nada menos que Jeanne Moreau) estupenda: las dos cosas que yo más anhelaba ser y tener. Casarse con una Jeanne Moreau no es fácil, tampoco lo es ser realmente un escritor. Por aquellos días, yo tenía una vaga idea de que no era sencillo ni una cosa ni la otra, pero no sabía hasta

40 La Notte (La noche) es una película italo-francesa de 1961, del género drama psicológico, dirigida por Michelangelo Antonioni. Protagonizada por Marcello Mastroianni, Jeanne Moreau y Monica Vitti en los papeles principales. Ganadora del Oso de Oro en el Festival Internacional de Cine de Berlín, del Premio David de Donatello y del premio Nastro d'Argento del Sindacato Nazionale Giornalisti Cinematografic iItaliani (SNGCI). Más información disponible en http://www.imdb.com/title/tt0054130/ 
qué punto eran dos cosas muy complicadas, sobre todo la de ser escritor. Yo vi La noche y empecé a adorar la imagen pública de esos seres a los que llamaban escritores. Me gustaron, en un primer momento, Boris Vian, Albert Camus, Scott Fitzgerald y André Malraux. Los cuatro por su fotogenia, no por lo que hubieran escrito." 41 Este pequeño apartado nos expresa la primera influencia, directa o indirecta del ejercicio literario que manifestó el escritor barcelonés. La imagen, la influencia y la impronta que Mastroianni entregó a ese personaje fueron uno de los empujones que recibió Vila-Matas para llevar a cabo su proyecto narrativo. De esta forma el paratexto El mal de Montano, perfectamente podríamos entenderlo como el mal de Pontano, haciendo referencia a la cualidad de enfermedad del trabajo literario. ${ }^{42}$

La referencia hipertextual se encuentra explícitamante desarrollada en la estructura de literalización que se presenta en la novela. Rosario Girondo escribe un diario, que se transforma en una novela, que se constituye como la identidad, la nueva identidad de un sujeto: hacer la vida a través de la literatura, hacer literatura a través de una impostura literaria. Impostura que Giovani Pontano hace real a través de su práctica en primera instancia seduciendo a Valentina Gherardini y en segunda instancia a través de las palabras que intercambió con su mujer Lidia, donde una frase de su pasado -con la cual sedujo a su esposa- es reutilizada por ella, no siendo capaz él mismo de reconocerse en la frase.

"Lidia: Esta mañana tú aún dormías y yo estaba despierto. Poco a poco, saliendo del sueño... he sentido tu respiración ligera. Entre el pelo que te tapaba la cara... te he visto los ojos cerrados. He sentido cómo la conmoción se me ponía en la garganta... y tenía ganas de gritar y despertarte... porque tu cansancio era demasiado profundo y mortal.

\footnotetext{
${ }^{41}$ Enrique VILA-MATAS, “Escribir es dejar de ser escritor", in: Barcelona Review, 23, 2001. http://www.barcelonareview.com/23/s_escribir.htm

${ }^{42}$ Las referencias a Mastroianni son constantes en la literatura Vilamateana, una suerte de motivo literario, de ahí que podamos relacionar la concepción del Pontano/Montano como resorte o percutor del futuro hombre construido a base de citas. Cristina Oñoro Otero vuelve a reparar en esta relación en su intervención leída en la librería La central MNCARS en Madrid, el 29 de febrero del 2008 a razón del lanzamiento del libro de ensayos El viento ligero en Parma, en el cual el segundo ensayo se titula "Mastroianni-sur-Mer", y vuelve a ahondar en dicha relación, encontrándose con otros juegos literarios como el siguiente "«Quiero ser Pereira», decía Mastroinanni. Tabucchi es de mi familia literaria, digo yo ahora mientras recuerdo que quise ser Mastroianni y éste quiso ser Pereira y que Pereira visita a Tabucchi y que Tabucchi quiso ser la sombra de Pessoa y que yo, en otro tiempo, quise ser la sombra de Tabucchi para poder ser la sombra de la sombra y que Pessoa quiso ser «el pirata resumen de toda la piratería en su auge» y vivió en una especie de delirio de ser otro, de ser todo lo otro para ser así no la voz de un individuo sino un mundo entero de voces de pronóstico grave" (40-41).
} 


\section{Recursos estilísticos en la producción narrativa de las novelas}

Bartleby y compañia y El mal de Montano de Enrique Vila-Matas

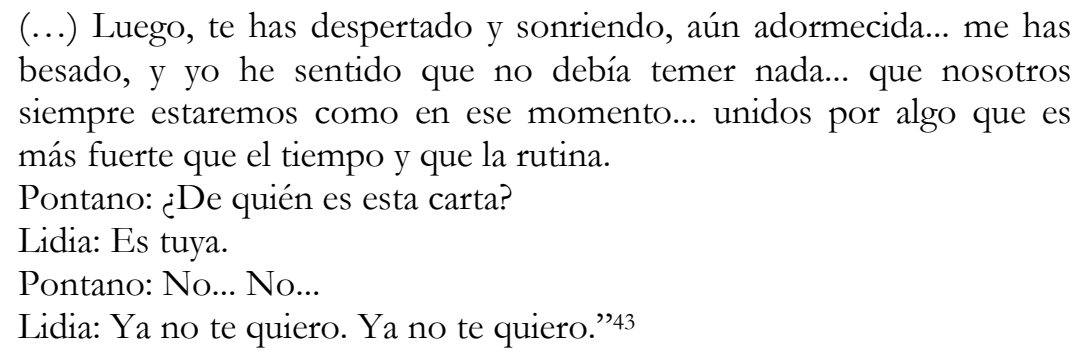

Esta imposibilidad de reconocimiento propio, es la aplicación de la impostura. Pontano se formula como un individuo a través de la literatura, todas sus relaciones se constituyen a través de esa fórmula en que el mundo de la ficción literaria mediatiza todo a su alrededor a la vez que fuerza la naturalidad propia del ser humano.

La relación con sus amigos, con sus interlocutores, con las mujeres que seduce, con su esposa, siempre parten de la tesitura de la ficcionalidad. Por lo tanto Vila-Matas toma como hipertexto la construcción de este personaje para desarrollar el tópico en El mal de Montano donde Rosario Girondo construye su identidad, su historia y sus relaciones a partir de la ficcionalidad que le permite la literatura, la capacidad de ser uno y ser varios a través de los libros, y no reconocerse y no ser el mismo, deviniendo vacío, la capacidad de la desaparición y reformulación de una individualidad a través de la literatura. Por lo tanto La Notte, la figura de Giovani Pontano, y su actuar, serían el hipotexto a través del cual el hipertexto vilamateano de El mal de Montano se estructura.

\section{Conclusiones}

Finalmente para Vila-Matas el misterio de la desaparición sólo podría ser develado desde una lectura de los mismos discursos de los escritores del no, convirtiéndose en lectores del no y entendiendo cómo esta deconstrucción del sujeto y del entramado solo pueden ser comprendidas a través de la elaboración y el análisis de la complicada red que presentan los recursos intertextuales; pues, la red lingüística que se presenta a través de los textos y la historia, parece sostener de mejor manera, los hilos de ciertas realidades, y a través de su análisis exhaustivo es más probable revelar la impostura, y entender esa decisión del hombre, de devenir vacío. Ahora antes de devenir imperceptible, el proceso literario se debe construir en base a una poética personal, en la cual la intertextualidad es una herramienta que singulariza la escritura del catalán.

La capacidad exploratoria del autor le permite llegar a este espacio descrito como experimental, la construcción de su proyecto narrativo posibilita la creación de esta cartografía literaria a través de la cual dispone sus museos literarios, sus colecciones, sus archivos. El escritor al realizar el ejercicio de narrar construye un concepto de realidad propio a partir de la incorporación de material erudito (intertextualidad, cita, plagio,

${ }^{43}$ Fragmento de La notte de Antonioni. 
alusión a heterogéneos campos culturales) buscando construir una realidad alterna propia, una realidad literaria la que a juicio del escritor sería la única práctica que nos permitiría comprendernos y comprender el sinsentido que nos rodea. De esta forma, el catalán propone el desplazamiento de la literatura a un campo distinto, fundamentalmente porque para él no existe distinción entre ficción y realidad; por lo tanto, construye una dualidad que entrega una nueva característica a la literatura, la posiciona en ese espacio de incertidumbre, ese espacio liminar donde la semantización de la realidad a través de las complicadas redes metatextuales y literarias generan un espacio de realidad similar al espacio autoficcional desde donde narra el autor.

Los procedimientos que previamente señalamos como nuestros objetos de estudio (intertextualidad, hipertextualidad, síndrome literario, entre otros) los analizamos en torno a su funcionalidad en relación al proyecto vilamateano. Y cómo cada una de sus cualidades permite la creación de estas novelas, que como expresamos anteriormente se formulan como un texto hibrido que presenta esa construcción denominada ensayonarrado o narración-ensayo, Vila-Matas ha señalado en relación a esto;

Gabastou: Has publicado muchos ensayos sobre todo en la prensa, reunidos después en libros. ¿Son el contrapunto reflexivo de tus ficciones o extensión de las mismas?

V-M: Está todo estrechamente ligado, del mismo modo que ensayo y ficción se entrelazan últimamente en casi todo lo que hago. Perder teorías, en este sentido -quizás por ser ensayo narrado o narración reflexiva-, se acerca más al género en el que me encuentro más a gusto, me divierto más, me siento más libre, en definitiva. Dublinesca es algo diferente, porque es más novela que otra cosa. La parte ensayística que podría haber incluido en Dublinesca, esta vez va aparte y es el ensayo narrado titulado Perder teorías. ${ }^{44}$

Esta cualidad le permite en ambas novelas incluir un fuerte componente metatextual, pues a medida que se desarrolla la fábula de ambas novelas también se desarrolla esa parte de reflexión en torno a los procesos que no solo definen los síntomas de los sujetos que describe en dichas obras, sino que también reflexionan sobre el estado de la literatura, el estado paradigmal de nuestro contexto sociohistórico y el estado de funcionamiento de las estructuras seculares de la literatura. Para desarrollar estos planteamientos construye complicadas redes intertextuales, las que suelen formar un texto lúdico cargado de referencias, que plantean ese mise en abyme donde un lector instruido suele perderse buscando nuevos textos o nuevas recomendaciones, o un lector casual comprende nuevos niveles de lo literario despertando la curiosidad hermenéutica.

${ }^{44}$ Fragmento de Vila-Matas, pile et face, en Argol en 2010, conferencia. 